\title{
Balance of Structure-Building Forces in Selenium-Based Self-Assembled Monolayers
}

Andrey Shaporenko ${ }^{1}$, Jan Müller ${ }^{2}$, Tobias Weidner ${ }^{1}$, Andreas Terfort ${ }^{2}$, Michael Zharnikov $^{1}$

${ }^{1}$ Angewandte Physikalische Chemie, Universität Heidelberg, 69120 Heidelberg, Germany

${ }^{2}$ Anorganische und Angewandte Chemie, Universität Hamburg, 20146 Hamburg,

\section{Germany}

\section{Supporting Information}

The synthesis of the BPnSe compounds is described elsewhere. ${ }^{1}$ The gold and silver substrates were prepared by thermal evaporation of $200 \mathrm{~nm}$ of gold or $100 \mathrm{~nm}$ of silver $(99.99 \%$ purity) onto mica or polished single crystal silicon (100) wafers (Silicon Sense) primed with a 5 $\mathrm{nm}$ titanium adhesion layer. The mica substrates were preliminary annealed at $320{ }^{\circ} \mathrm{C}$ for 24 hours prior to the metal evaporation, done at the same temperature. The evaporated films were polycrystalline, with a grain size of $20-50 \mathrm{~nm}$ for $\mathrm{Si}$ or a terrace size of $100-200 \mathrm{~nm}$ for mica as observed by atomic force microscopy and scanning tunneling microscopy. The grains predominantly posses a (111) orientation. ${ }^{2,3}$ The SAMs were formed by immersion of freshly prepared gold substrates into a $1 \mathrm{mmol}$ solution of BPnSe compounds in ethanol for $24 \mathrm{~h}$.

The fabricated films were characterized by X-ray photoelectron spectroscopy (XPS), high-resolution XPS (HRXPS), infrared reflection absorption spectroscopy (IRRAS), angle resolved near-edge X-ray absorption fine structure (NEXAFS) spectroscopy, ellipsometry, and contact angle goniometry. The results of all experimental techniques agree quite well, but XPS 
and NEXAFS spectroscopy data are mostly representative for the observed effects, which was the reason that the respective data were exclusively selected for the communication.

The XPS experiments were carried out under UHV conditions at a base pressure < $1.5 \times 10^{-9}$ mbar. The measurements were performed using a $\mathrm{Mg} \mathrm{K} \alpha \mathrm{X}$-ray source and a LHS 11 analyzer. The spectra acquisition was carried out in normal emission geometry with an energy resolution of $\approx 0.9 \mathrm{eV}$. The $\mathrm{X}$-ray source was operated at a power of $260 \mathrm{~W}$ and positioned $\sim 1.5$ $\mathrm{cm}$ away from the samples. The energy scale was referenced to the $\mathrm{Au} 4 \mathrm{f}_{7 / 2}$ peak of alkanethiolate-coated gold at a binding energy (BE) of $84.0 \mathrm{eV}^{3}$ For each sample, a wide scan spectrum and the $\mathrm{C} 1 \mathrm{~s}, \mathrm{O} 1 \mathrm{~s}$, Se 3d, and either Au 4f or Ag 3d narrow scan spectra were measured. XPS spectra were fitted by symmetric Voigt functions and Shirley-type backgrounds. To fit the $\operatorname{Se} 3 \mathrm{~d}_{5 / 2,3 / 2}$ doublet we used two peaks with the same full width at half maximum (FWHM), the standard ${ }^{4}$ spin-orbit splitting of $\sim 1.18 \mathrm{eV}$ (verified by fit), and a branching ratio of 3:2 $\left(\operatorname{Se} 3 \mathrm{~d}_{5 / 2} / \mathrm{Se} 3 \mathrm{~d}_{3 / 2}\right)$. The fits were performed self-consistently; the same fit parameters were used for identical spectral regions. The effective thickness of the BPnSe SAMs was determined from the $\mathrm{I}_{\mathrm{C} 1 \mathrm{~s}} / \mathrm{I}_{\mathrm{Au} 4 \mathrm{f}}$ and $\mathrm{I}_{\mathrm{Cls}} / \mathrm{I}_{\mathrm{Ag} 3 \mathrm{~d}}$ intensity ratios, assuming a standard exponential attenuation of the photoelectron signal and using the attenuation lengths reported in ref 5 (the procedure has been verified for several reference samples).

NEXAFS spectroscopy measurements were performed at the HE-SGM beamline of the synchrotron storage ring BESSY II in Berlin, Germany. The spectra acquisition was carried out at the $\mathrm{C}$ K-edge in the partial electron yield mode with a retarding voltage of $-150 \mathrm{~V}$. Linear polarized synchrotron light with a polarization factor of $\sim 82 \%$ was used. The energy resolution was $\sim 0.40 \mathrm{eV}$. The incidence angle of the light was varied from $90^{\circ}$ ( $\boldsymbol{E}$-vector in surface plane) to $20^{\circ}$ ( $\boldsymbol{E}$-vector near surface normal) in steps of $10-20^{\circ}$ to monitor the orientational order in the SAMs. This approach is based on the dependence of the cross-section of the resonant 
photoexcitation process on the orientation of the electric field vector of the synchrotron light with respect to the molecular orbital of interest (so-called linear dichroism in X-ray absorption). ${ }^{6}$ Raw NEXAFS spectra were normalized to the incident photon flux by division through a spectrum of a clean, freshly sputtered gold sample. The photon energy (PE) scale was referenced to the pronounced $\pi_{1}{ }^{*}$ resonance of highly oriented pyrolytic graphite at $285.38 \mathrm{eV}^{7}$

The average tilt angles of the biphenyl moieties in the BPnSe films were estimated using a standard evaluation procedure. For this purpose, the intensity of absorption resonances $I$ was monitored as a function of the X-ray incidence angle $\theta$ and the resulting dependence evaluated according to the theoretical expression (for a vector-type orbital) ${ }^{6}$

$$
I(\alpha, \theta)=A\left\{P \times \frac{1}{3}\left[1+\frac{1}{2} \cdot\left(3 \cdot \cos ^{2} \theta-1\right) \cdot\left(3 \cdot \cos ^{2} \alpha-1\right)\right]+(1-P) \frac{1}{2} \sin ^{2} \alpha\right\},
$$

where $A$ is a constant, $P$ is a polarization factor of the $\mathrm{X}$-rays, and $\alpha$ is the average tilt angle of the molecular orbital.

For the evaluation, the most intense $\pi_{1}{ }^{*}$ resonance has been selected; its TDM is oriented perpendicular to the ring plane. The expression (1) was slightly modified to include the twist of the biphenyl backbones. ${ }^{8,11}$ A herringbone packing of these backbones with a twist angle of $32^{\circ}$, which is close to that for bulk aromatic compounds, was assumed.9,10,12,13 Note that a herringbone structure of the aromatic moieties optimizes the intermolecular interaction in the densely packed 2D-layers and is, in particular, typical for aromatic SAMs on Au. ${ }^{10,13,14}$ To avoid normalization problems, not the absolute intensities but the intensity ratios $I(\theta) / I\left(90^{\circ}\right)$ were analyzed, ${ }^{6}$ where $I(\theta)$ and $I\left(90^{\circ}\right)$ are the intensities of the $\pi_{1}{ }^{*}$ resonance at X-ray incidence angles of $\theta$ and $90^{\circ}$. The accuracy of the average tilt angle values is $\pm 3-5^{\circ}$, which is just a general accuracy of the NEXAFS experiment and data evaluation. However, most of these values were reproduced in the control experiments with a higher accuracy. 


\section{References}

(1) Müller, J.; Terfort, A. Inorg. Chim. Acta, 359(15) (2006) 4821-4827

(2) Köhn, F. Diploma Thesis, Universität Heidelberg, Heidelberg, Germany, 1998.

(3) Heister, K.; Zharnikov, M.; Grunze, M.; Johansson, L. S. O. J. Phys. Chem. B 2001, 105, 4058.

(4) Moulder, J. F.; Stickle, W. E.; Sobol, P. E.; Bomben, K. D. Handbook of X-ray Photoelectron Spectroscopy, Chastian, J., Ed.; Perkin-Elmer Corp.: Eden Prairie, MN, 1992.

(5) Lamont, C. L. A.; Wilkes, J. Langmuir 1999, 15, 2037.

(6) Stöhr, J. NEXAFS Spectroscopy; Springer-Verlag: Berlin, 1992.

(7) Batson, P. E. Phys. ReV. B 1993, 48, 2608.

(8) Shaporenko, A.; Adlkofer, K.; Johansson, L. S. O.; Tanaka, M.; Zharnikov, M. Langmuir 2003, 19, 4992.

(9) Dhirani, A.-A.; Zehner, W.; Hsung, R. P.; Guyot-Sionnest, P.; Sita, L. J. Am. Chem. Soc. 1996, $118,3319$.

(10) Himmel, H.-J.; Terfort, A.; Wöll, Ch. J. Am. Chem. Soc. 1998, 120, 12069.

(11) Zharnikov, M.; Küller, A.; Shaporenko, A.; Schmidt, E.; Eck, W. Langmuir 2003, 19, 4682.

(12) Chang, S.-C.; Chao, I.; Tao, Y.-T. J. Am. Chem Soc. 1994, 116, 6792.

(13) Azzam, W.; Cyganik, P.; Witte, G.; Buck, M.; Wöll, Ch. Langmuir 2003, 19, 8262.

(14) Cyganik, P.; Buck, M.; Azzam, W.; Wöll, C. J. Phys. Chem. B 2004, 108, 4989. 